\title{
No Decrease in Central Venous Pressure When Epinephrine-Induced Hypotension Occurs
}

\author{
Jian-jun Yang, Xiao-li Xu, Jin-chun Shen, Wei-yan Li and Zhi-qiang Zhou \\ Department of Anesthesiology, Jinling Hospital, School of Medicine, Nanjing University, Nanjing, P.R. China.
}

Received August 28, 2008; Revised April 2, 2009; Accepted April 14, 2009; Published April 16, 2009

Previously $(1,2)$ we have shown that local infiltration with epinephrine-containing solutions on nasal field or scalp may produce hypotension because of the possible activation of $\beta_{2}$ receptors. However, whether central venous pressure (CVP) will change when epinephrine-induced hypotension occurs remains unknown. We hypothesized that CVP should also decrease when hypotension happened.

The present study was approved by the Ethics Committee of Jinling Hospital and conducted according to the Helsinki Declaration, and the prior written informed consents were obtained from all patients. Twenty patients without premedication (male/female: 13/7, age: $36 \pm 12$ years, weight: 65 $\pm 10 \mathrm{~kg}$, American Society of Anesthesiologists physical status: I or II) undergoing elective endoscopic sinus surgery with general anesthesia were included. After anesthesia induction with midazolam $0.03 \mathrm{mg} / \mathrm{kg}$, rocuronium $0.8 \mathrm{mg} / \mathrm{kg}$, and target controlled infusion with propofol $4 \mu \mathrm{g} / \mathrm{ml}$ and remifentanil $5 \mathrm{ng} / \mathrm{ml}$, anesthesia was maintained with propofol 3.5-4 $\mu \mathrm{g} / \mathrm{ml}$ and remifentanil $3.5-4 \mathrm{ng} / \mathrm{ml}$ by target controlled infusion. All the patients were mechanically ventilated to keep the end tidal carbon-dioxide tension around $35 \mathrm{mmHg}$. About $20 \mathrm{~min}$ after the mechanical ventilation, the surgeons decongested the nose with four cotton swabs containing oxymetazoline and lidocaine for $3 \mathrm{~min}$. Thereafter, they locally infiltrated epinephrine $20 \mu \mathrm{g}$ with normal saline $4 \mathrm{ml}$ on nasal septum, middle nasal meatus, and inferior nasal concha before surgery and all the infiltration was accomplished within
25-30 s. The previous studies have shown that the lowest and the highest arterial blood usually occur at 1.5 and $3 \mathrm{~min}$ after local infiltration, respectively ${ }^{1,2}$. Therefore, mean arterial pressure (MAP), heart rate (HR), cardiac output (CO), and systemic vascular resistance (SVR) monitored by impedance cardiography and CVP monitoring via central venous catheter were recorded at 4 time points: before local infiltration (baseline) and 1.5, 3, and 4.5 min after the beginning of local infiltration.

Statistical analysis was performed by statistics package for social science of 13.0-version. Comparisons were made by analysis of variance for repeated measurements followed by the least significant difference test for multiple comparisons. Difference was considered to be significant at $P<$ 0.05. Compared with the baseline, MAP and SVR decreased and HR and $\mathrm{CO}$ increased significantly $(P<0.01)$ at $1.5 \mathrm{~min}$, then recovered at 3 and 4.5 min. But CVP did not change significantly during this period. (Table 1). We presumed that the decrease in MAP was due to the decrease in SVR (1-5) induced by the activation of $\beta_{2}$ receptors $(1,3)$; the increase in $\mathrm{CO}$ was due to the activation of $\beta_{1}$ receptors ${ }^{1}$ and the reflex to the decrease in SVR, and the increase in HR was due to the activation of $\beta_{1}$ receptors and the baroreflex to the decrease in $\operatorname{MAP}(1,2,4,5)$.

Corresponding Author: Jian-jun Yang, Department of Anesthesiology, Jinling Hospital, School of Medicine, Nanjing University, Nanjing, P.R. China. yjyangjj@126.com 
Table. 1 Changes in MAP, HR, CO, SVR, and CVP after the beginning of local infiltration $(n=20)$

\begin{tabular}{lllll} 
& Baseline & $1.5 \mathrm{~min}$ & $3 \mathrm{~min}$ & $4.5 \mathrm{~min}$ \\
\hline $\mathrm{MAP}(\mathrm{mmHg})$ & $77 \pm 8$ & $59 \pm 11^{*}$ & $78 \pm 10$ & $75 \pm 8$ \\
\hline $\mathrm{HR}(\mathrm{beat} / \mathrm{min})$ & $62 \pm 6$ & $77 \pm 10^{*}$ & $63 \pm 7$ & $65 \pm 7$ \\
$\mathrm{CO}(1 / \mathrm{min})$ & $4.6 \pm 0.5$ & $5.3 \pm 0.8^{*}$ & $4.9 \pm 0.6$ & $4.8 \pm 0.6$ \\
$\mathrm{SVR}\left(\mathrm{dyn} \cdot \mathrm{s} \cdot \mathrm{cm}^{-5}\right)$ & $1225 \pm 203$ & $805 \pm 269^{*}$ & $1188 \pm 216$ & $1168 \pm 197$ \\
$\mathrm{CVP}\left(\mathrm{cmH}_{2} \mathrm{O}\right)$ & $7.3 \pm 1.3$ & $7.0 \pm 1.5$ & $7.3 \pm 1.5$ & $7.2 \pm 1.4$ \\
\hline
\end{tabular}

Values are mean \pm SD. MAP, HR, CO, SVR, and CVP are recorded at 4 time points; *, significant drop from baseline. ${ }^{* *} P<0.01$, compared with the baseline.

In the present study, no decrease in CVP was observed. This is a good explanation for that the fluid expansion is not a good measure to prevent epinephrine-induced hypotension (4), which remains unknown in our previous study (5).

The decreased SVR indicated that systemic arteries and arterioles, as resistance vessels, dilated significantly after epinephrine infiltration on nasal field; however, the stable CVP implied that systemic venules and veins, as capacitance vessels, dilated indistinctively. Further studies are needed to explore the underlying mechanisms for the differences of epinephrine on resistance and capacitance vessels.

\section{REFERENCES}

[1]. Yang JJ, Zheng J, Liu HJ, Liu YX, Shen JC, Zhou ZQ. Epinephrine infiltration on nasal field causes significant hemodynamic changes: hypotension episode monitored by impedance-cardiography under general anesthesia. J Pharm Pharmaceut Sci, 2006, 9: 190-197.

[2]. Yang JJ, Cheng HL, Shang RJ, Shen JC, Shi JX, Wang HD, et al. Hemodynamic changes due to infiltration of the scalp with epinephrine-containing lidocaine solution: a hypotensive episode before craniotomy. J Neurosurg Anesthesiol, 2007, 19: 31-37.

[3]. Linton NW, Linton RA. Haemodynamic response to a small intravenous bolus injection of epinephrine in cardiac surgical patients. Eur J Anaesthesiol, 2003; 20: 298-304.

[4]. Yang JJ, Liu J, Duan ML, Zhou ZQ, Li WY, Xu JG. Lighter general anesthesia causes less decrease in arterial pressure induced by epinephrine scalp infiltration during neurosurgery. J Neurosurg Anesthesiol, 2007, 19: 263-267.

[5]. Li WY, Zhou ZQ, Ji JF, Li ZQ, Yang JJ, Shang RJ. Relatively light general anesthesia is more effective than fluid expansion in reducing the severity of epinephrine-induced hypotension during functional endoscopic surgery. Chin Med J (Engl), 2007, 120: 1299-1302. 